\title{
Expertise in Sports Medicine Among Family Physicians: What are the Benefits?
}

\author{
F. Baarveld ${ }^{*}, 1$, B.J. Kollen ${ }^{2}$ and K.H. Groenier ${ }^{1}$ \\ ${ }^{1}$ Department of General Medicine of Groningen University, The Netherlands \\ ${ }^{2}$ Research Bureau, Isala klinieken Zwolle, The Netherlands
}

\begin{abstract}
Objectives: To obtain a better understanding of the benefits of expertise in sports medicine among family physicians in non-acute sports related leg injuries.

Methods: Observational study based on information on patient characteristics, physicians' care and recovery gathered with questionnaires from physicians and patients during the first consultation and from patients at 1, 3, 6 and 12 months after inclusion.
\end{abstract}

Results: No differences in treatment effects were found between patients of family physicians with no, some or much interest in sports medicine and attended relevant postgraduate courses with regard to sport discontinuation, perceived benefit of consultation and satisfaction about the recovery of the sports injury and the physicians' approach of care. Respondents experienced a gradual decline in sport discontinuation throughout the year following inclusion. Likewise, mean satisfaction rates diminished for the physicians' approach of care in all patients, but the appreciation remained high throughout.

Conclusion: The results of this study show no added benefit of expertise in sports medicine among family physicians for the recovery of non-acute sports related injuries to the lower extremity.

\section{INTRODUCTION}

In the Netherlands the familiar general practice with one family physician is gradually being transformed into a practice with multiple physicians [1]. Improved continuity of care and the development of different disorder specific levels of expertise among family physicians within a practice are considered advantages related to this development. However, whether this development in primary care generates better patient care is unknown.

The importance of sports is substantial. In the Netherlands about 8 million people (53\% of the population) participate in sports activities at an organized or non-organized level [2]. In addition to its health benefits concomitant injuries may occur. In this country of 16 million inhabitants annually 2.7 million sports injuries are reported, of which 1.1 million are presented to the office of a health care facility [3]. At present rather than sports injury the comprehensive term sports related injury is used [4]. This term denotes any injury that affects the individuals' ability to engage into sports activities irrespective of where this injury was sustained. It therefore also incorporates injuries sustained during non-sports activities. The overall incidence of non-acute sports related injuries is expected to increase, because in particular the proportion of middle aged and older men and women that becomes involved in sports is steadily increasing [5]. To date no scientific data on non-acute sports related injuries in primary care is available. Therefore, we conducted a study to address the following question. Does

*Address correspondence to this author at the Department of General Medicine of Groningen University, The Netherlands;

E-mail: f.baarveld@med.rug.nl expertise in sports medicine among family physicians result in less sport discontinuation, better patient understanding of the injury and coping with the injury and more patient satisfaction with regard to the physicians' approach of care and the recovery of the injury in patients with non-acute sports related injuries to the lower extremity?

\section{METHODS}

This observational study is part of a longitudinal unblinded randomized controlled trial, in which the primary care provided by family and sports physicians (operating in a primary care setting) was studied in patients with non-acute sports related injuries to the lower extremity [6]. This study was conducted between 2000 and 2002 in three northern Dutch regions (Heerenveen, Zwolle and Groningen). Within each region patients were recruited for this trial during a period of 6 months. As these recruitment periods were consecutive, the total enrolment period amounted to one and an half years overcoming any possible injury related seasonal impacts.

Following obtaining informed consent opaque envelopes were used for the randomization procedure of patients. Subsequently patients consulted the allocated family or sports physician at the primary care facility site within a week.

For this observational study only information gathered from the questionnaires completed by the family physician and their patients was used. For this purpose the group of family physicians was categorized based on their interest in sports medicine. As a consequence unequal patient groups emerged. However, the distribution of patients within groups (no: $\mathrm{n}=20$ or $16.7 \%$, some: $\mathrm{n}=71$ or $59.2 \%$ and much: $\mathrm{n}=$ 29 or $24.2 \%$ ) is similar to the distribution of interest found among Dutch family physicians at large [7]. 


\section{Study Population}

\section{Family Physicians}

Regional clusters of family physicians operating in three northern regions in the Netherlands were approached and their members invited to participate in this trial. In this way the participation of only sports-minded family physicians was avoided. Within these clusters most physicians operate from solo practices. Patients were enrolled into the trial by 83 family physicians of which 59 were allocated to provide primary care by the randomization procedure.

\section{Patients}

Participating patients were recruited from the group of patients that consulted their family physician for a non-acute sports related injury to the lower extremity.

\section{Inclusion Criteria}

Inclusion of patients with sports related injuries was based upon satisfying the following criteria. The injury was sustained at least two weeks prior to consulting the family physician; the injury was confined to the lower extremity and was presented as a first event. No age limit was included.

\section{Dependent and Independent Variables}

The primary outcome variable constitutes sport discontinuation measured from the first month following inclusion onwards. This variable consists of a 5 point ordinal scale that varies from 'stopped all sports activities' to 'no sport discontinuation' and is dichotomized to enable logistic regression analysis. In addition 3 secondary outcome variables were used. One variable pertained to the perceived benefit of the consultation by the patient. It was measured from the first month onwards. Information was derived from 4 items about the patients' understanding of the injury and ability to manage and cope with their injury. Each items was scored on a 3 point ordinal scale from 'much better or improved' to 'less often or deteriorated' depending on the nature of the question. Patients' satisfaction regarding the physicians' approach of care and satisfaction about the recovery of the injury was scored on a 10 point numerical rating scale. The former was recorded from the first consultation onwards, while the latter was scored from the third month onwards. These dependent variables were related to the following independent variables: Duration of symptoms before the first consultation of the physician (varies between ' $2-3$ weeks' and 'more than 12 months'), sports objective (competitive/non-competitive), type of sport, work-out frequency (varies between 'less than 1' and 'more than 4' times a week), patients' age, patients' gender, physicians' professional experience (expressed in number of years), relevant postgraduate courses attended by the physician (yes/no), physicians' administered care (subdivided into instruction, clarification, therapy and referral) and physiotherapy (yes/no).

In total 7 questionnaires were administered. These questionnaires were completed during the first consultation by the family physician, sports physician and patient and at 1, 3, 6 and 12 months by the patient. The research proposal was approved by the STEG ethnics committee in Amsterdam.

\section{Statistical Analysis}

Baseline characteristics were compared using Student $t$, Fisher's Exact and Chi squared trend tests (Table 1). A logistic regression model was developed for the dichotomous dependent variable sport discontinuation $(0$ - stopped all sports activities/more or same sport discontinuation, 1 - less or no sport discontinuation) for each time point of measurement. Cronbach's Alpha coefficients were used to determine the internal consistency of the 4 items of the perceived benefit of the consultation by the patient variable. For the testing of the secondary outcome variables for each time point of measurement a separate univariate General Linear Model (GLM) was used for the aggregated variable perceived benefit of the consultation by the patient, satisfaction regarding the physicians' approach of care and satisfaction about the recovery of the injury. In all applied models at least the dichotomous group variable interest in sports medicine $(0-$ no/some, 1 - much) and attended relevant postgraduate courses $(0-$ no, 1 - yes) were included.

Longitudinal changes within and between groups were tested with GLM statistics for repeated measurements. Groups were based upon the interest in sports medicine variable.

Compliance with the assumptions of the multivariable models was tested for all variables involved. In the event the data did not fit the assumptions of the model independent variables were dichotomized based upon their median or feature present or absent.

\section{RESULTS}

Fifty-nine family physicians and 120 patients participated in this study. The response rate of questionnaires gradually diminished from 100 percent at the first consultation to 90 percent at 12 months after inclusion. No significant differences were found at baseline between relevant patient characteristics. Internal consistency was determined for the 4 items from the perceived benefit of consultation variable. At 1, 3, 6 and 12 months the following respective Cronbach's Alpha coefficients were found: 0.85, 0.84, 0.87, 0.88.

\section{Individual Time Points}

In the analysis of each individual time point of measurement none of the applied regression models that included at least the dichotomous variables interest in sports medicine and attended relevant postgraduate courses, even following the addition and correction of other determinants into the model, showed significance among selected variables.

\section{Longitudinal Time Points}

\section{Sport Discontinuation}

With regard to sport discontinuation no significant difference in change over time between groups of patients was found $(\mathrm{F}=0.82, p=0.44)$. However, the reported change over time for sport discontinuation decreased significantly within groups $(\mathrm{F}=4.62, p=0.007)$ (Fig. 1). The shape of this relationship was linear $(\mathrm{F}=8.75, p=0.004)$, while a cubic interaction was observed between time and interest ( $\mathrm{F}$ $=5.91, p=0.004)$. 
Table 1. Baseline Characteristics of Patients Based on Family Physician Groups (Dichotomized Variable of Interest in Sports Medicine)

\begin{tabular}{|c|c|c|c|c|}
\hline \multirow{2}{*}{ Characteristic } & \multicolumn{2}{|c|}{ Interest } & \multirow{2}{*}{$\mathbf{N}$} & \multirow{2}{*}{ P Value ${ }^{1}$} \\
\hline & No/Some & Much & & \\
\hline Age: mean (sd) & $32,98(13,69)$ & $32,86(13,67)$ & 120 & $0.97^{2}$ \\
\hline Gender: \% male & 71,4 & 65,5 & 120 & $0.64^{3}$ \\
\hline Body mass index: mean (sd) & $23,44(3,19)$ & $23,89(3,33)$ & 108 & $0.54^{2}$ \\
\hline Type of sport: modus & soccer & soccer & 115 & $0.55^{3}$ \\
\hline Sports objective: $\%$ non-competitive & 63 & 55,6 & 108 & $0.50^{3}$ \\
\hline Work-out frequency: median & $2 \mathrm{x}$ & $2 \mathrm{x}$ & 117 & $0.53^{3}$ \\
\hline Duration of each work out: median & 1,5 hours & 1,5 hours & 115 & $0.94^{3}$ \\
\hline Period of sport discontinuation: median & $1-4$ weeks & $<1$ week & 95 & $0.50^{3}$ \\
\hline Duration of symptoms prior to first consultation: median & $6-13$ weeks & $3-6$ weeks & 120 & $0.21^{4}$ \\
\hline Site of injury: modus & knee & knee & 120 & $0.42^{3}$ \\
\hline
\end{tabular}

Significance level (tested two sided at $\alpha \leq 0.05) ;{ }^{2}$ Unpaired T test $;{ }^{3}$ Fisher's Exact test $;{ }^{4} \mathrm{X}^{2}$ trend.

\section{Perceived Benefit of Consultation}

No significant difference in change over time between $(\mathrm{F}$ $=1.58, p=0.21)$ and within $(\mathrm{F}=1.54, p=0.21)$ groups of respondents was found.

\section{Satisfaction About the Physicians' Approach of Care}

No significant difference in change over time between groups of patients $(\mathrm{F}=1.20, p=0.31)$ was found for the patients' satisfaction about the physicians' approach. The reported change over time for this satisfaction decreased significantly within groups $(\mathrm{F}=8.14, p<0.0005)$. This decline was both linear $(\mathrm{F}=11.63, p=0.001)$ and quadratic $(\mathrm{F}$ $=11.61, p=0.001)$ (Fig. 2).

\section{Satisfaction About the Recovery of the Sports Injury}

No significant difference in change over time between ( $F$ $=0.97, p=0.38)$ and within $(\mathrm{F}=2.66, p=0.09)$ groups of respondents was observed.

\section{DISCUSSION}

This study found no benefits of expertise of the family physician in this group of patients with non-acute sports related injuries to the lower extremity. Interest in sports medicine and attended postgraduate courses did not affect the patients' sport discontinuation, perceived benefit of the consultation and satisfaction with regard to the recovery of the sports injury and the physicians' approach of care. These results agree with those of the study of Baarveld et al. [6]. Baarveld's study found no differences in sport discontinuation and physicians' approach to care between the care provided by family and sports physicians.

Although they did report a higher initial satisfaction rate about the recovery of the injury among patients treated by the sports physician, this difference had disappeared at 12 months.

In this observational study we found a gradual decline of sport discontinuation in all patients. This sport discontinuation eventually faded away almost completely. Most probably this decline represents the healing effect of time. It is unlikely this decline is generated by the physicians' care, because on average patients consulted their physician only twice.

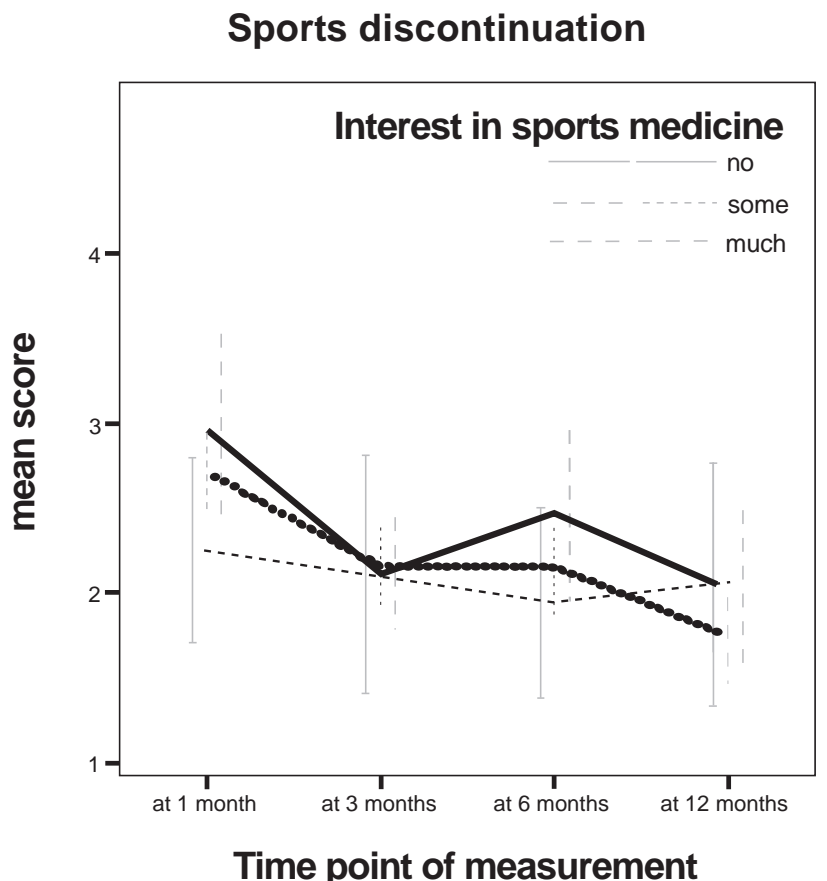

Fig. (1). Mean course of sport discontinuation over time with $95 \%$ confidence intervals based on physicians' interest in sports. Mean score: 1 - no sport discontinuation; 2 - less sport discontinuation; 3 - same sport discontinuation; 4 - more sport discontinuation; 5 stopped all sports activities.

Although significant the decline in satisfaction rate about the physicians' approach is relative as it amounts to a little less than one point on a ten point scale. Moreover, at 12 months this satisfaction was still rated at slightly above 7 points. 


\section{Satisfaction about physicans' apprroach}

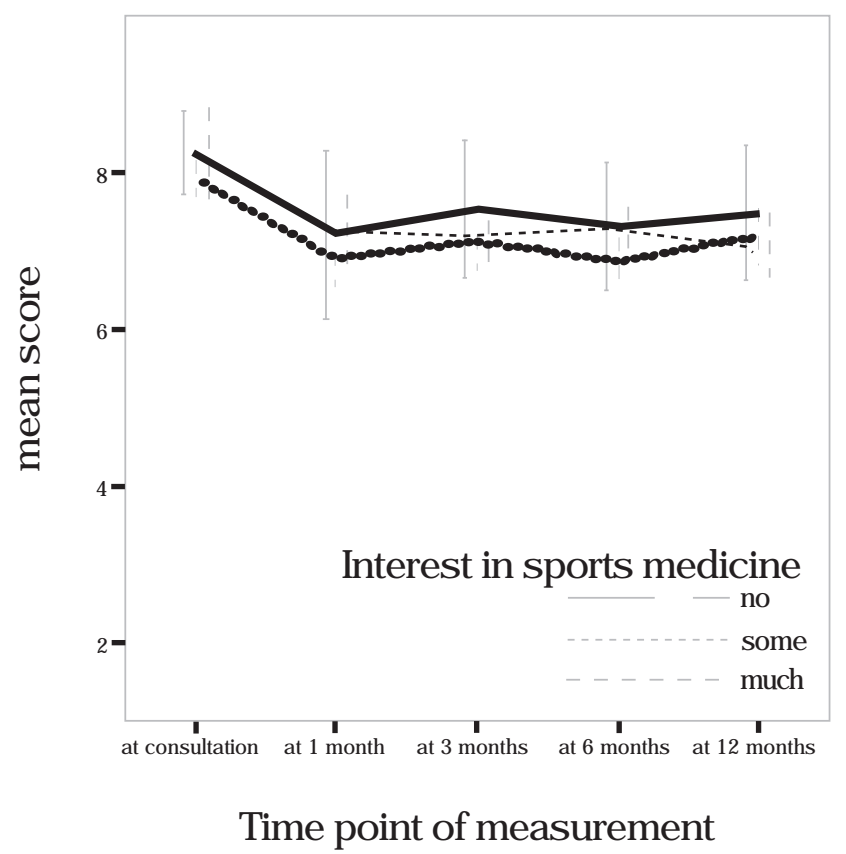

Fig. (2). Mean course of satisfaction over time with $95 \%$ confidence intervals about physicians' approach of care based on physicians' interest in sports medicine. Mean score ranges from 1 (dissatisfied) to 10 (satisfied).

Even though patient groups were similar at baseline with respect to relevant patient characteristics, apart from the duration of symptoms prior to the first consultation, no information is available that demonstrates equal distribution of severity of injuries among patient groups. However, at inclusion following the randomization procedure no data were available about the family physicians' status with regard to his or her interest in sports medicine nor was information forwarded about the severity of the injury. This information became available at the completion of the first questionnaire. Nevertheless, random differences in severity of the injury can not be ruled out. Therefore, instead of categorization prior randomization is the preferred method to limit or eliminate imbalances between groups. Furthermore, no clinimetric testing was conducted prior to the administration of questionnaires. As a consequence reliability, validity and responsiveness of these tools have not been established. In the process of dichotomizing dependent and group variables relevant clinical cut-off points were elected. However, these cut-off points are arbitrary to some extent.

Much is unknown about the effects of specific expertise among family physicians as a primary care instrument. The literature is deficient on this topic. This exploratory study is intended as a first initiative to assess this phenomenon. Although this study failed to show any effects of specific expertise among family physicians in this patient population, due to methodological flaws and lack of contrast between family and sports physicians, more research is needed in order to elucidate any possible benefits. This requires the implementation of randomized controlled trials with adequate power and contrast.

\section{REFERENCES}

[1] Kenens RJ, Hingstman L. Cijfers uit de registratie van huisartsen. Peiling 2003. Nederlands Instituut voor Onderzoek van de Gezondheidszorg 2003.

[2] Schmikli SL, Backx FJG, Bol E. Sportblessures nader uitgediept. Bohn Stafleu Van Loghum, Houten/Diegem 1995.

[3] Hulshof NA, van Essen GA, Andela M, Friele RD. Patiënten over preventie door hun huisarts. Huisarts Wet 1998; 41: 117-20.

[4] Sport, bewegen en gezondheid. Naar een actief kabinetsbeleid ter vergroting van de gezondheid door en bij sport en beweging. Ministerie van Volksgezondheid, Welzijn en Sport. September 2001.

[5] Rapportage Sport 2003. Sociaal Cultureel Planbureau. Den Haag, April 2003.

[6] Baarveld F, van Enst GC, Schuling J, Bosveld HEP, Meyboom-de Jong B. Behandeling en Verloop van Niet-acute Sportgerelateerde Problemen van de Onderste Extremiteit. Een Vergelijkend Onderzoek tussen Huisarts en Sportarts. In: Sportgerelateerde Problemen in de Huisartspraktijk. Frank Baarveld. Elsevier gezondheidszorg, Maarsen 2004.

[7] Baarveld F, Versteegh SM. Preventie van sportgerelateerde problemen: een taak voor de huisarts? Tijdschrift voor Sociale Gezondheidswetenschappen 2004; 82: 285-289. 